\title{
WOMEN IN MECHANICS: A STUDY ON GENDER RATIO USING SELECTED JOURNALS FROM THE YEARS 2002 AND 2017
}




\begin{abstract}
Even though there have been efforts for many years now to attract more women to engineering fields, technical professions are still clearly dominated by men. The following study examines the gender ratio concerning authorship within two popular journals in the field of mechanics: Computer Methods in Applied Mechanics and Engineering (CMAME) and Journal of the Mechanics and Physics of Solids (JMPS). The examined periods include the years 2002 and 2017. Beyond that, we paid attention to the individual citations of the articles and the first author's $\mathrm{h}$-indices as well.

In these journals, the percentage of female authors in the field of mechanics is significantly lower than the number of female graduates and doctoral candidates in the field would suggest. Even if there was a slight increase in publications of women in the investigated period, male scientists' contributions were still dominating the research field of mechanics in 2017.
\end{abstract}

Keywords: gender gap, engineering, STEM Disciplines, first author, authorship, h-index

Words: 7940

After studying Modern German Literary History, Sociology and Psychology, Melanie Kaesler worked for several years in publishing in the field of editing and proofreading. In 2015, she worked for the press office of RWTH Aachen University, and since 2018, she is employed as a research assistant at the Institute of Applied Mechanics at RWTH Aachen University.

In October 2011, Carmen Leicht-Scholten held a visiting professorship in the field of "Gender and Diversity Management in the Engineering Sciences", located at the Institute for Software Engineering and Theoretical Computer Science at the Faculty IV of the TU Berlin. She is Professor for "Gender and Diversity in Engineering" at the Faculty of Civil Engineering at RWTH Aachen University. Since spring 2012, she is dean of studies at the Faculty of Civil Engineering.

Stefanie Reese received her doctorate in 1994, after her diploma in civil engineering, with a thesis on the theory and numerics of the stability behavior of hyperelastic solids. In 2002, she habilitated in the field of mechanics with a thesis on the thermomechanical modeling of rubber-like polymer structures. From 2000 to 2005, she was professor at the Ruhr-University Bochum, Faculty of Civil Engineering, AG Numerical Mechanics and Simulation Technology. Afterwards she was professor at the Technical University Carolo-Wilhelmina of Braunschweig, Faculty of Mechanical Engineering, Institute of Solid State Mechanics, until 2009. Since 2009, she is Professor of Applied Mechanics at the RWTH Aachen University. 


\section{Introduction}

Gender underrepresentation has long existed in science, technology, engineering, and mathematics (STEM), although women have made substantial gains in participation in scientific research. Despite all measures, such as the annual Girls' Day and the National Pact for Women in STEM disciplines, women are still rarely represented in technical professions.

Engineering sciences are particularly apparent due to their low number of women. In their study, Cardador and Hill even describe engineering as one "of the most male-dominated professions in the United States" (Cardador/Hill 2018: 95). Burke describes the STEM sector as "white and male“. (Burke 2007: 10). He points out that women and disabled people have historically been underrepresented in the STEM sector - both in research and in business settings (Ibid). Another conspicuous feature in the area of equal opportunities that is widely discussed concerns the so-called "leaky pipeline" (Etzkowitz/Ranga 2011: 131). Accordingly, the proportion of women on the academic career ladder decreases from rung to rung. In his study, Etzkowitz describes women in engineering and technology careers as "lost at every educational transition stage" (Ibid: 132).

The fact that the proportion of women is falling when it comes to top positions, despite increasingly higher education degrees and promotional measures, seems to be a global phenomenon. This is suggested by studies from Switzerland, the USA and Europe (Miller/Wai 2015; Schubert/Engelage 2011; Herschberg/Berger 2015). In principle, this decline in the number of women can be observed across all subjects, but it seems to be particularly noticeable in the STEM disciplines (Blickenstaff 2005). While some researchers have struggled for decades to find explanations for this, Etzkowitz's research points out that not every woman who interrupts her academic career fails professionally. Rather, the migration from academia to other professions offers new perspectives for women. He therefore contrasts the negatively connoted term "leaky pipeline" with the term "vanish box" (Etzkowitz/Ranga 2011: 131). In order to be able to classify the proportion of female authors, it is first necessary to look the number of female graduates and the proportion of female doctoral candidates in the engineering sector in recent years in order to obtain a reference figure.

In 2007, the proportion of female graduates in the EU was around $25 \%$ in engineering sciences (Eurostat 2021). Compared with other subjects such as the humanities and social sciences, but also compared with mathematics and the natural sciences, the difference between the genders was thus most pronounced here (Ibid). The gap between women and men was more marked in science, mathematics, and computer science than in other subjects; in engineering, manufacturing, and construction, the ratio of male to female graduates was nearly 3 to 1 (Ibid). 
The proportion of female graduates in mechanical and process engineering in Germany is about $20 \%$; in 2009, it was 19 \% (Quaiser-Pohl, S. 16). Although the overall proportion of doctoral students in engineering has risen steadily in Germany since the 1970s, quadrupling since 1992, the proportion of female doctoral students here was only 14\% in 2006 (Acatech 2021: 18). Data from 2019 show that women are still significantly outnumbered when it comes to PhDs in the Federal Republic of Germany, although the upward trend continues: 18, 3 \% of PhDs in engineering are women (Destatis 2021). The proportion of women who have successfully completed their doctorates in mechanical and process engineering in 2017 is already at 18 \% (Nationaler Pakt für Frauen in MINT-Berufen 2020).

Data from 2019 show that women are still significantly outnumbered when it comes to PhDs in the Federal Republic of Germany, although the upward trend continues: $18,3 \%$ of PhDs in engineering are women (Destatis 2021). The proportion of female professors in Germany in 2019 was almost 19\% overall, and $13.6 \%$ in the engineering sciences (Statista 2021).

In the United States, the representation of females among doctorate recipients in engineering for 2002 was $18 \%$ (National Science Foundation 2021: 13). In 2017, the proportion of women here was already 24.9\%. (National Center for Science and Engineering Statistics 2021).

From 2016-2019, the proportion of women among employed scientists in the engineering and science sector in the European Union was approximately 40 \% (Eurostat 2020). According to the National Science foundation, the proportion of female graduates in mechanical engineering in the USA was between $12.4 \%$ and $15.3 \%$ from 2004 to 2014 (National Science Foundation 2020).

Another indication of figures on female researchers in the field of mechanics is provided by data on GAMM (Gesellschaft für Angewandte Mathematik und Mechanik). The annual GAMM meeting gathers renowned scientists from the field of applied mathematics and mechanics, so that it represents a solid cross-section of the active community in this field. Using the respective Books of Abstract numbers from 2006 (Berlin) and 2017 (Ilmenau), we can show that there was a female proportion here of 2,8\% (2006) and 8\% (2017) if we exclude female mathematicians (GAMM Book of Abstracts 2006/GAMM Book of Abstracts 2017). All data provide information on the sections, mini symposia and keynote lectures.

Several studies have analyzed possible reasons for the gender disparity such as the incompatibility of job and family and the supposed male image of engineering sciences. In this context, Gorlov speaks of a deterrent traditional image of engineering (Gorlov 2009). The lack of role models, and the associated feeling of not belonging, is also repeatedly cited as a reason for the lack of women in the STEM disciplines (Herrmann et al. 2016). Women seem to be aware of the difficulties associated with breaking into a male domain (Henwood 2010). Considering the studies concentrating on the reasons for women's "nonentrance" into science and engineering, it is impossible to ignore the supposed stereotypes that appear to discourage women when it comes to entering a male domain (Fouad 2019: 446). 
For all this, there is no doubt that gender justice, especially in the STEM disciplines, functions as a flagship and decisive economic factor in a democratic society. It is brought in connection with climate justice und economic growth (Alber et al. 2018; Elomäki 2015).

A society that wants to remain competitive on a long-term basis needs gender equality as well as active participation of women in the entire labor market in order to remain sustainable (Beede et al. 2011,Leicht-Scholten 2007). Considering a demographic change, far-reaching changes in the workplace and modified role models in private life, no society can afford to ignore the issue of equal opportunities. If access to certain areas of education is more difficult for half of the population, or if well-educated women are excluded from the world of work, this has a negative impact on the economic stability in the long-term. Involving women centrally in economic life has a positive effect on the prosperity of the entire society, increases productivity and is the driving force for the economic development of a country especially with regard to the fields of science, technology, engineering and math (Ibid). Consequently, the continued underrepresentation of women in scholarly activities slows down the scientific progress of any country. In Germany, for instance, there are repeated complaints that the proportion of engineers in the country is not sufficient to counteract the existing shortage of skilled workers (Kottmann et al. 2016). Thus, the low participation of women in the STEM sector is not just a private problem, but also "a major workforce problem" (Verdugo-Castro et al. 2018: 984).

In general, technological innovations serve as a yardstick for the economic success of a country and this in turn guarantees prosperity and social peace (Elomäki 2015). It is therefore not surprising that the existing gender gap in the technical field is currently widely discussed. Hence, it is even more striking that, from an international perspective, women are still a clear minority, especially in the engineering sector, and that gender injustice remains in this field. Even though, they have made enormous progress in education and the workplace during the past fifty years and the representation of women in the STEM sector has declined, men still outnumber women when it comes to science and engineering (Hill/Corbett/Rose 2010). Therefore, the analysis of an existing gender gap in mechanics and engineering is a central research concern not only from a perspective of equality, but also from a societal and economic point of view (Leicht-Scholten/Breuer/Tulodetzki/Wolffram 2011). In order to take a closer look at the existing low level of women's participation in the research process in the field of mechanics, the following study focuses on gender-specific differences with regard to scientific authorship as well as on the respective scope of particular publications. Scientific publications in considerable journals together with their scope are appropriate instruments to demonstrate the individual active participation in the research process. Career progression depends on public perception, including publication in prestigious journals. Scientific publications underpin research productivity and effect the visibility of women within the scientific community. Particularly the first authorship of peer-reviewed publications is an indicator for academic success. 
In our survey, we have concentrated on two renowned journals in order to compare the proportion of female authors and first authors with that of male ones. This direct comparison allows a conclusion to be drawn concerning an existing gender gap in this thematic field. The following principle applies: in order to prove gender inequalities, it is necessary to research and depict reality accordingly. Thus, to examine the active participation of female researchers in the field of mechanics, the following study focuses on the proportion of female authors, first authors and the respective scope of their publications. By analyzing authorship in 2002 and 2017, we can also determine whether there is a positive trend reversal of female participation in this area.

Since they represent a central measured variable when it comes to the quality of scholarly contribution, we also looked at the individual citations. If articles are cited frequently, we automatically assume that the author is influential and that the scientific contributions have a significant impact on the field although being aware on gender biases in citation practices (Squazzoni et al. 2021).

Hence, in order to state something about the scope of their publications in addition to the active participation of women in the research process, we decided to take the first author's h-indices and their article's citations into account as well. From these, we determined the respective percentiles and compared them with each other. To identify a potential trend reversal, we recorded these data for both journals and both years. Thereby, we hope to find out whether women actually remain unnoticed with regard to their research, as some studies suggest [e.g. ...]. Maliniak, Power and Walter succeeded in proving that "[...] women are systematically less cited as men after controlling for a large number of variables including year of publication, venue of publication [...] and institutional affiliation" (Maliniak et al. 2013: 889). The authors assume that women do not quote themselves as often as men do. According to that, men seem to prefer the same gender when it comes to using research literature (Ibid). The $h$-index is a recognized measure to determine the view of a scientist in expert circles as well. High $\mathrm{h}$-indices stand for high research impact and high productivity and it "assesses the quality and quantity of published research articles" (Carter et al. 2017: 1547). For this reason, we have also determined these values and compared them with each other.

Based on the current research literature, it can be assumed that women are still a clear minority in the field of engineering and are therefore less represented as authors in the journals examined by us compared to men. Considering decades of efforts on the part of politicians worldwide, we would expect to see a slight trend towards closing the gender gap in the field of engineering.

In general, it can be assumed that women will be a clear minority in both journals in 2002 and 2017, both in terms of authors and first-time authors. Therefore, female representation would remain uneven across STEM fields and this appears to be a worldwide phenomenon. 


\section{Research background}

Numerous scientific publications have addressed the topic of the gender gap in the STEM area. For several decades, researchers have repeatedly noted that women are clearly underrepresented in the field of science and engineering, although the number of female graduates in this field is continuously increasing. While some scientists look for reasons for this imbalance and point out possible ways out of the misery, others emphasize the high importance of gender justice for the whole society. The reasons for the low percentage of women in the STEM disciplines that are repeatedly cited include a lack of role models and a gender stereotypical upbringing that already directs girls in a certain direction (Herrmann et al. 2016). Stereotypical images that contradict the female self-concept also discourage women from choosing to study in the STEM field (Lewis et al. 2017). In her study from 2013, Hatmaker investigates to what extent interpersonal interactions in a professional context contribute to the fact that women in engineering sometimes feel devalued. To find out something about the women's professional identity in a gendered profession the author interviewed a total number of 52 female engineers from the USA. According to this, women describe that in the course of interactions their gender is always in the foreground, followed by their professional expertise. They also feel treated differently from their male colleagues and are entrusted with other tasks (Hatmaker 2013).

Beyond that, the individual publication situation stands in the center of the academic consideration as well.

Several studies indicate that women are underrepresented when it comes to scientific publications, whereas some surveys explicitly pursue the question to what extend women's expertise in science and engineering is recognized. In 2014, for instance, Joshi investigated the extent to which the gender composition of a team affects the perception of female expertise. He concludes that "[...] gender-integrated teams with a higher proportion of highly educated women are more productive in disciplines with a greater female faculty representation." (Joshi 2014: 202) and that "Male actors who strongly identify with their gender are more likely to favor men irrespective of their educational status, penalizing women who have attained higher educational status by rating them lower than less-educated women in the team." (Ibid: 220). The expertise of highly educated women was used to a greater extend in teams with a higher proportion of women than in teams composed of men (Ibid: 228). Therefore, it seems that at least in male-dominated settings a high educational status has a negative effect on the perception of men.

Other studies show a negative correlation between female gender and authorship. This concerns biomedical engineering, audio engineering, clinical chemistry, medicine as well as geoscience (Pico 2020). It seems that especially in prestigious journals female authors are underrepresented. Holman, Fox and Hauser have also found that especially in wealthy countries, notably Japan, Germany, and Switzerland, 
there were fewer female authors than in poorer ones with regard to science, technology, engineering, mathematics, and medicine (Holman/Fox/Hauser 2018).

Young and her colleagues were able to exhibit a "[...) a lack of gender diversity in conference authorship in audio engineering" (Young et al. 2018: 328). According to that, women are a clear minority when it comes to audio engineering conferences (Ibid).

Even in the medical field, where women are overrepresented, female first authors make up less than $50 \%$ of all first authors (Sidhu et al. 2009). Another paper examined the first female authorship in high impact medical papers published from 1994 to 2014. The authors could prove that, based on all articles examined, just $34 \%$ of all first-authors were female (Filardo et al. 2014). Even though the representation of women was significantly higher in 2014 than 20 years ago, it has plateaued in recent years and yet declined in some journals (Ibid).

In his paper, Annesley evaluated the participation of women as authors in the field of clinical chemistry. Therefore, he collected data for total female authorship, female first author, and female first or corresponding author. In both of the journals considered, female authors accounted for a share of more than $40 \%$ (Annesley 2020). With regard to the sector of Clinical Chemistry, the proportion of first authors is accompanied by the proportion of female PhDs, and women are thus "well represented as authors" in this field. (Ibid: 969).

West looked at gender disparities with regard to scholarly authorship from 1960-2009. His research shows that women represent $21.9 \%$ of the gender-identified authorships in the entire JSTOR network dataset (West et al. 2013).

As far as the gender gap in terms of the $\mathrm{h}$-index and individual article citations is concerned, several studies exist as well. However, these do not explicitly examine the $h$-index in the STEM or engineering area. Carter, Smith and Osteen study the h-index and its impact on social work faculty, for instance. They succeeded in proving that the h-index of men in all faculty ranks was higher than that of female authors. Besides, "the gender gap was the greatest at the Full Professor level" (Carter et al. 2017: 1547).

Another study deals with the existing gender effect in the field of psychology. It points out the importance of this inequality for society in general. The authors demonstrate a gender effect on the $\mathrm{h}$ index and refer to the different gender networks. The fact that women tend to use more female networks, while men fall back on male-dominated networks, may therefore further cement an already existing gender gap. Networks that consist only of men apparently represent an additional hurdle for women that must be overcome (Geraci et al. 2015).

Several authors have also examined the situation of female researchers with regard to individual article citations. Maliniak and his colleagues evaluated peer-reviewed publications from 1980 to 2006 to show that women were cited less frequently overall than male authors (Mailinak et al. 2013). However, 
hardly any study is dealing with the influence of research texts by female authors especially in the field of science and engineering.

\section{Materials and Methods}

In this study, we capture and evaluate data for two journals in the field of engineering and mechanics for the years 2002 as well as 2017 and finally compared it with each other. In detail, we examined the journal Computer Methods in Applied Mechanics and Engineering (CMAME) and the Journal of the Mechanics and Physics of Solids? (JMPS). We have chosen these two journals for our study since they are renowned respective the field of computational engineering. According to SCimago in 2020, both journals are listed among the 25 most influential journals concerning mechanical engineering and both journals exhibit broad scope, from fundamental concepts in mechanics to the analysis of novel phenomena and applications. Moreover, CMAME leads the SCImago Journal Rank's list of the most influential journals in Computational Mechanics in 2019 (SCImago 2020).

In the course of the study, we collected data for three categories: the authors, the h-index and the articles' citations. At first, we concentrated on the authors. We classify the data for this into several further categories: total number of authors, number of authors of unknown gender, number of first authors of unknown gender, number of female authors for each article whether the first author was female. In CMAME, the first names of the authors were abbreviated in places by only one letter, so that it has not always been possible to determine the gender unambiguously. In addition, there were isolated unisex names, especially from the Asian area, which were listed completely but could not be assigned to a gender despite intensive efforts, also via the search engines as well as the universities.

From these data, the percentages of female authors, articles with female first authors, authors of unknown gender, and articles where a first author of unknown gender were calculated.

In order to compare the scope and influence of scientific publications with regard to gender aspects, we focused on the h-index as well. Hereto, we recorded - in a second step - the h-index for female and male first authors in both journals and subsequently determined the respective average values. The h-index was collected at the time of data collection, and thus in 2020. The study relies on data from Scopus to ascertain the h-indices.

Finally, the third category of our study is dealing with the citations per article. Concerning this, we compared the respective average values for both sexes.

In total, we collected data for 1035 articles, including 716 from CMAME and 319 from JMPS, and data for 3089 authors, of which 913 can be attributed to JMPS and 2176 to CMAME. In 2002, there were an average of 9 articles per issue in CMAME and 9 in JMPS. In 2017, there were 32 in CMAME and 17 in JMPS. 
Since it is not possible to identify the diverse gender by means of the name, this is not considered in our investigation.

\section{Results}

As shown in Table 1, we could not determine the gender of 107 authors including 23 first authors. Measured by all authors and considering both issues, CMAME has a $4.9 \%$ share of authors of unknown gender.

\begin{tabular}{|l|l|l|}
\hline Journal & \multicolumn{2}{|c|}{ CMAME } \\
\hline Year & \multicolumn{1}{|c|}{2002} & 10 \\
\hline $\begin{array}{l}\text { First authors with un- } \\
\text { known gender }\end{array}$ & 13 & 65 \\
\hline $\begin{array}{l}\text { Authors with unknown } \\
\text { gender }\end{array}$ & 42 & 1619 \\
\hline Total number of authors & 557 & \multicolumn{1}{|c|}{2017} \\
\hline
\end{tabular}

Table 1. Total number of authors in CMAME in 2002 and 2017.

Related to CMAME and considering both issues, this makes a share of $3.2 \%$ of authors who we could not assign to any gender. In the second journal, we were able to dedicate all authors to one gender in both years. Therefore, the significance of our study is not significantly weakened.

Related to all articles from both journals, the result is an average value of 1.1 female first authors per issue. For JMPS there is a percentile of one female first author per issue and for CMAME it is 1.1 female first author per issue, see Table 2 .

\begin{tabular}{|l|l|l|l|c|}
\hline Journal & \multicolumn{2}{|c|}{ JMPS } & \multicolumn{2}{c|}{ CMAME } \\
\hline Year & 2002 & 2017 & 202 & 2.9 \\
\hline $\begin{array}{l}\text { Female first authors per } \\
\text { issue }\end{array}$ & 0.4 & 1.6 & 0.5 & 2.1 \\
\hline Total & \multicolumn{2}{|c|}{1.0} & \multicolumn{2}{c|}{1.1} \\
\hline
\end{tabular}

Table 2. Average number of female first authors per issue in JMPS and CMAME.

Taking into account all first authors, the percentage of women is below $10 \%$ for both journals and in both years, although there is a slight upward trend, see Table 4. This increase in female first authors in CMAME is one percentage point lower than in JMPS, although the proportion of women here was already almost as high in 2002 as in JMPS in 2017.

\begin{tabular}{|l|l|l|l|l|}
\hline Journal & \multicolumn{2}{|c|}{ JMPS } & \multicolumn{2}{c|}{ CMAME } \\
\hline Year & 2002 & 2017 & 2002 & 2017 \\
\hline
\end{tabular}




\begin{tabular}{|l|l|l|l|l|}
\hline Male first authors & 26 & 10 & 30 & 12 \\
\hline Female first authors & 16 & 13 & 11 & 11 \\
\hline
\end{tabular}

Table 3. Average $h$-index of the first authors by gender.

\begin{tabular}{|l|l|l|l|l|}
\hline Journal & \multicolumn{3}{|c|}{ JMPS } & \multicolumn{2}{c|}{ CMAME } \\
\hline Year & 2002 & 2017 & 2002 & 2017 \\
\hline Female first authors & $5 \%$ & $9 \%$ & $8 \%$ & $9 \%$ \\
\hline
\end{tabular}

Table 4. Percentage of female first authors, measured as a percentage of all articles.

Based on Figure 1, the difference between the sexes is already clearly visible at first glance. If all authors are taking into account, the number of both sexes has grown strongly over the years, but the proportion of female authors has increased many times over. Hence, as expected, the gender gap appears to be decreasing - at least when it comes to research-related activities such as publishing articles and papers. This development is particularly noticeable with JMPS. Nevertheless, even in 2017 the number of female authors is still significantly below that of men, considering the absolute numbers in both journals.
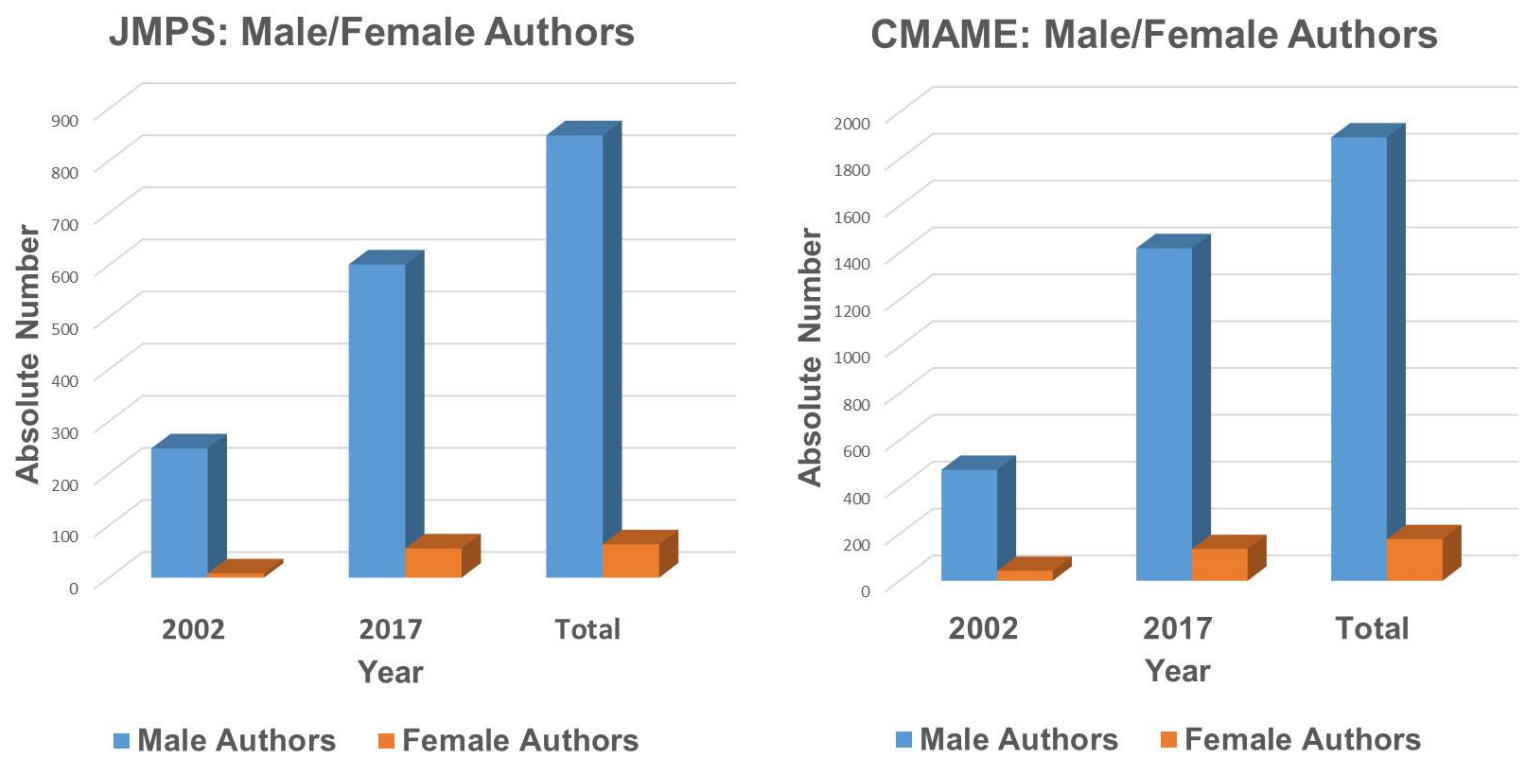

Figure 1. Absolute number of authors of JMPS and CMAME by gender.

In JMPS, the absolute number of female authors has increased sevenfold: from 8 in 2002 to 56 in 2017. The number of female first authors developed from 5 in 2002 to 19 in 2017 and has thus tripled. In CMAME, the number of female authors has tripled from 42 in 2002 to 135 in 2017. Nevertheless, the proportion of male authors is also significantly higher here. Whereas JMPS almost tripled the overall proportion of female authors, measured by all authors, from $3.1 \%$ in 2002 to $8.5 \%$ in 2017, as we can see in Figure 2, the percentage of female first authors developed from 4,5\% in 2002 to $9 \%$, in 2017, as we can see in Figure 4. 


\section{Ratio of Female/Male Authors "JMPS" 2002 by Gender}

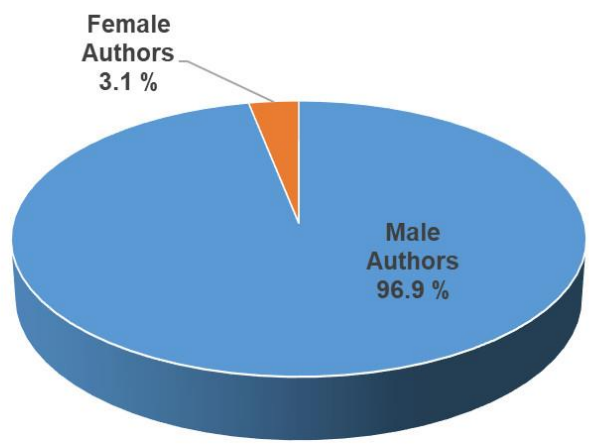

- Male Authors - Female Authors

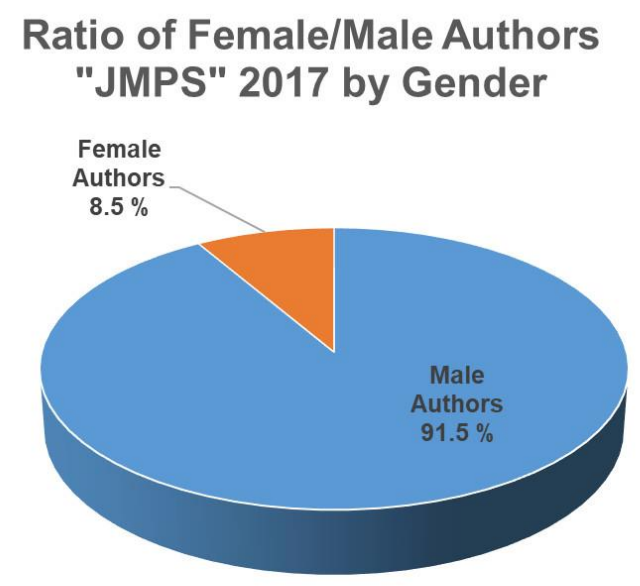

- Male Authors - Female Authors

Figure 2. Gender ratio of all authors in JMPS in 2002 and 2017.

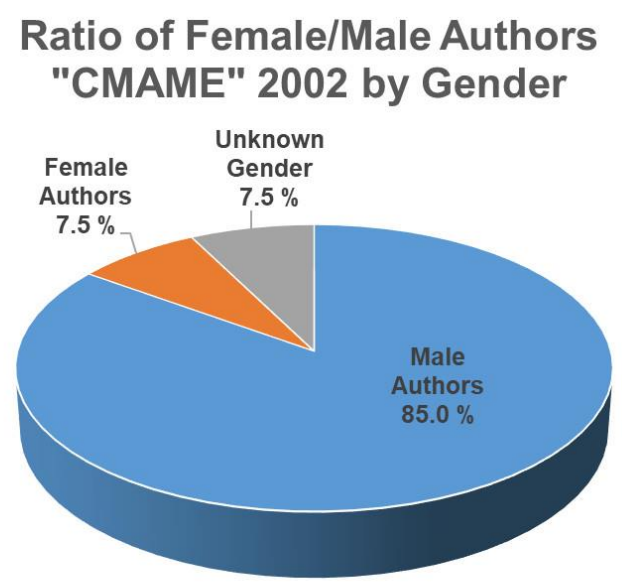

- Male Authors $\quad$ Female Authors

- Unknown Gender

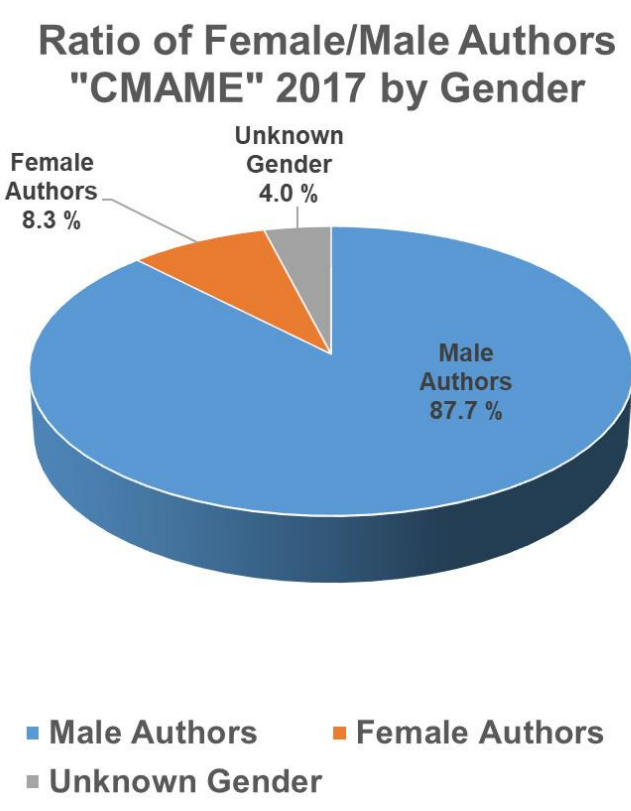

- Unknown Gender

Figure 3. Gender Ratio of authors in CMAME in 2002 and 2017.

As we can see in Figure 3, the percentage of female authors measured by all authors has increased from $7.5 \%$ in 2002 to $8.3 \%$ in 2017, which is actually only a very small increase. The absolute number of female authors has increased from 42 in 2002 up to 135 in 2017. Also the percentage of female first authors in CMAME slightly increased during this period from $8.2 \%$ in 2002 up to $8.8 \%$ in 2017 , see Figure 5. So it is noticeable that although the proportion of female first authors and co-authors in CMAME was 2002 already as high as in JMPS in 2017, it only increased very little by 2017, and is thus practically on a level with the proportion of female authors in JMPS, see Figure 4 and 5. 
Overall, we can see that although there has been a considerable increase in research contributions by female authors, the gap to male colleagues is still quite large. On average, there is an increase of circa 1 female first-time author per year, if both journals are considered, so we are not able to identify a real trend of improvement. Even taking into account the change in the proportion of female professors in the engineering sciences over the years, there is still a discrepancy: In Germany for instance, the proportion of women has developed from $6 \%$ in 2002, to $10 \%$ in 2014, to $14 \%$ in 2019 (Destatis 2014;). In the USA, the proportion of female professors in engineering was $21.1 \%$ in 2019 (Society of Women Engineers 2021). As discussed below, the proportion of female graduates and doctoral candidates in this field is also higher than the proportion of female authors would suggest.
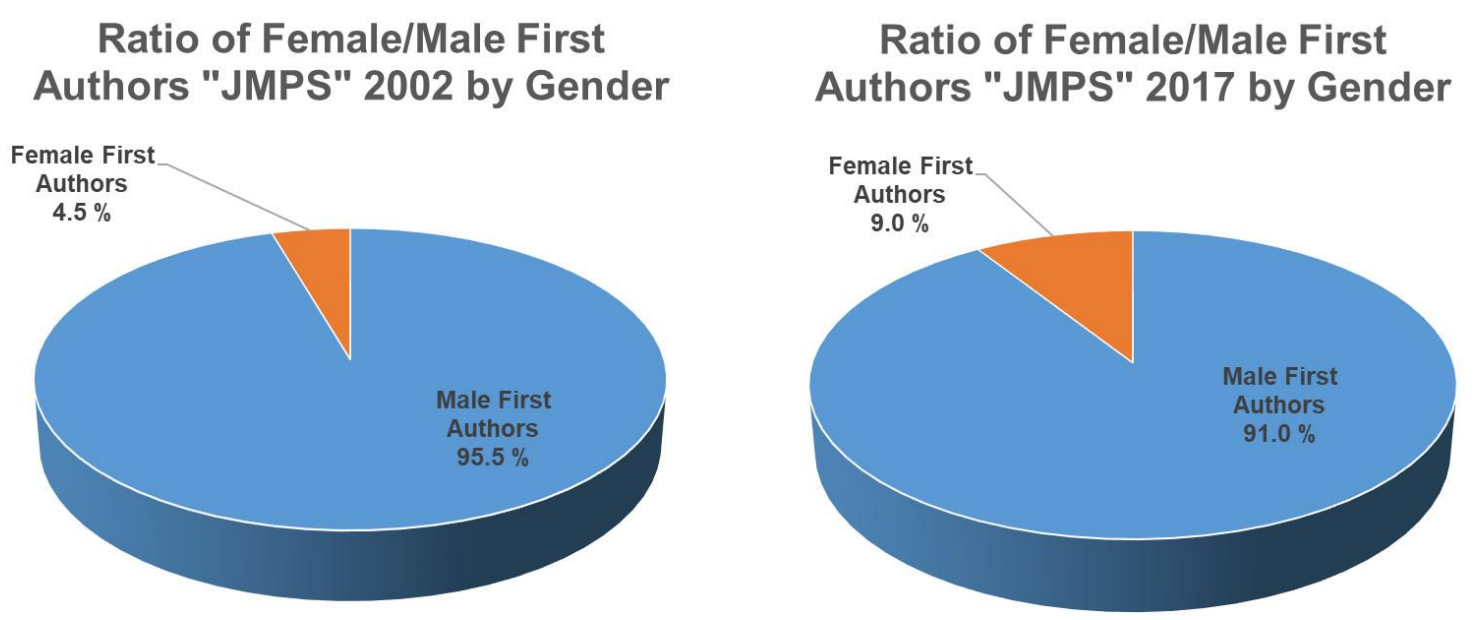

- Male First Authors - Female First Authors

- Male First Authors - Female First Authors

Figure 4: Gender ratio of first authors in JMPS in 2002 and 2017. 


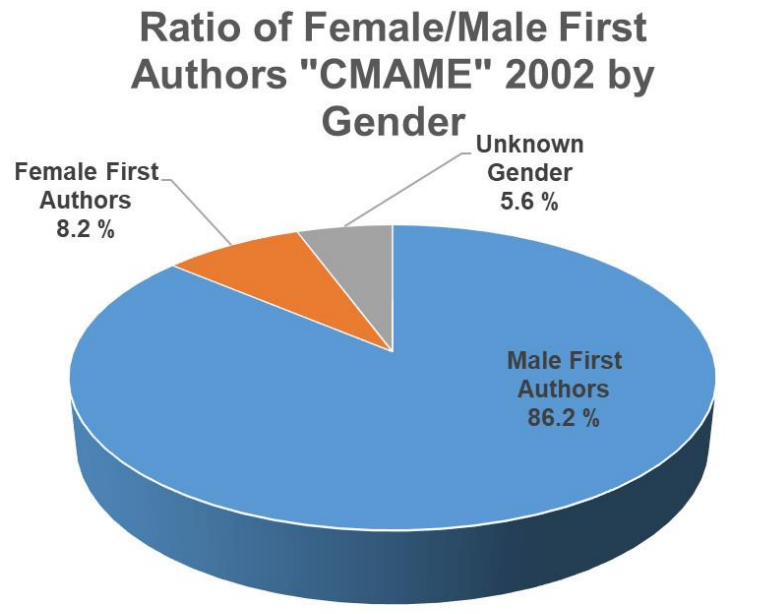

- Male First Authors $\quad$ - Female First Authors

- Unknown Gender

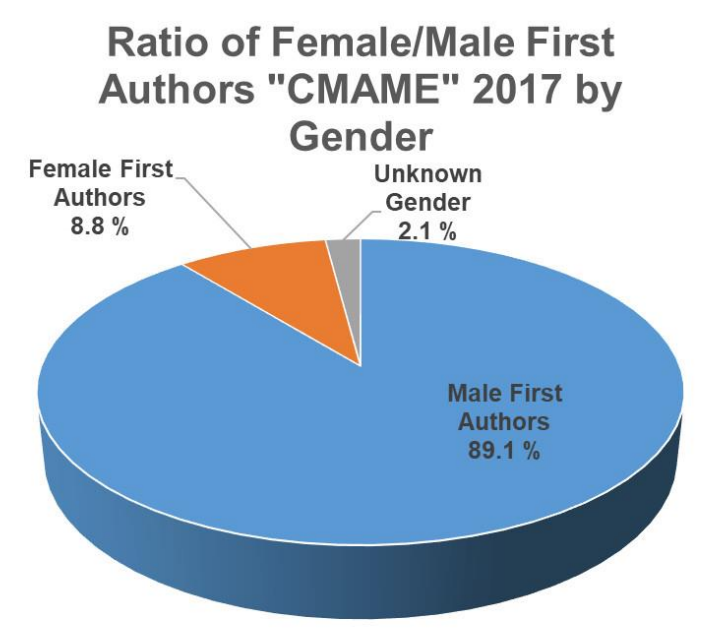

Male First Authors $\quad$ - Female First Authors
- Unknown Gender

Figure 5. Gender ratio of first authors in CMAME in 2002 and 2017.

Relating to the $\mathrm{h}$-indices of the first authors, we can demonstrate a convergence between the different sexes in the examined period under study. The bar graphs in Figure 6 reveal that in both journals there has been a convergence of the h-indices of both sexes. While in 2002 the average $h$-index of male first authors is still almost twice as high as that of female first authors, there is hardly any difference between the sexes in 2017. This applies to both journals and is remarkable as there is still a strong discrepancy between publications by men and women. Possible reasons for this are discussed below. In JMPS, the average h-index for men in 2002 is still significantly higher than for women at 26 compared to 16 , but in 2017, the value for women is slightly higher: 13 compared to 10 , see Table 3 . As discussed below, that could support the thesis that women have to perform better in order to be visible. In the second journal examined, the value for both sexes is almost identical for the year 2017, although in 2002 it was still almost three times higher on average for men than for women. For all first-time authors of JMPS applies: Their average h-index has decreased from 2002 to 2017. In summary, it can be concluded, that despite large differences in the number of authors, there is no great difference between the sexes in the scope of their respective research work when we look at the h-indices. 
$\mathrm{H}$-Index of Male/Female First

Authors in "JMPS" 2002 and

2017

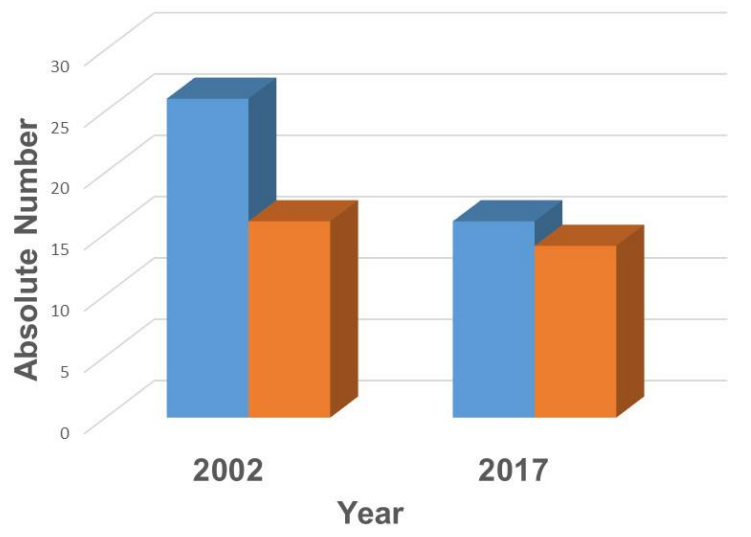

Male First Authors Female First Authors
$\mathrm{H}$-Index of Male/Female First

Authors "CMAME" 2002 and

2017

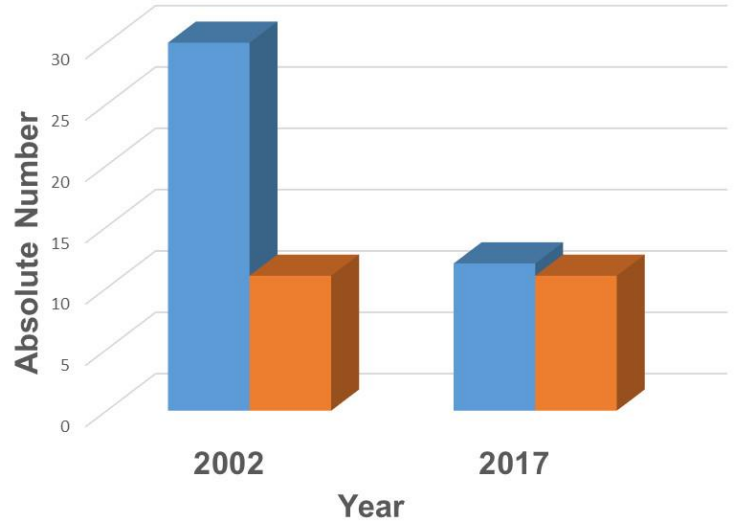

Male First Authors $\quad$ Female First Authors

Figure 6. Average h-index of the first authors.

Furthermore, we can see that all articles of male first authors published in JMPS were cited more as twice as often on average as those with female first authors, see Table 5. In 2017, the value of women's articles at 24 is higher than the value of male author's articles at 18. In CMAME, women's articles were cited on average 105 times whereas the articles of male authors were cited about 80 times. In 2017, the value for men at 26 is slightly higher than the average for female authors at 19 . Thus, the number of article citations for both sexes has decreased overall. In contrast to 2002 , the citations of male and female authors in 2017 are much closer together.

Further research is needed to better understand this positive development towards closing the gender gap. Because the deep gap between the active participation of men and women in science and engineering is still existing.

\begin{tabular}{|l|l|l|l|l|}
\hline Journal & \multicolumn{2}{|c|}{ JMPS } & \multicolumn{2}{c|}{ CMAME } \\
\hline Year & 2002 & 2017 & 2002 & 2017 \\
\hline $\begin{array}{l}\text { Citations for male first } \\
\text { authors }\end{array}$ & 119 & 18 & 80 & 26 \\
\hline $\begin{array}{l}\text { Citations for female first } \\
\text { authors }\end{array}$ & 45 & 24 & 105 & 19 \\
\hline
\end{tabular}

Table 5. Average number of citations.

\section{Discussion}


Despite a slight increase in female authors from 2002 to 2017, women are still a minority in this range, based on both journals, CMAME and JMPS. This concerns the first authors and the co-authors as well. Hence, there is obviously still a gender gap with regard to research in engineering and mechanics. The fact that the proportion of female first authors and co-authors in CMAME was in 2002 already as high as in JMPS in 2017 might be explained by its thematic orientation: Since 2006, more women than men have begun studying mathematics in Germany, for instance. In 2009, the proportion was already $52 \%$ (Quaiser-Pohl 2012: 15). Unlike JMPS, CMAME is much more mathematically oriented.

The fact that there is no difference in the $h$-indices despite this imbalance is striking. The reasons for this can only be speculated at this point. Thus, it could be that the selection of professional contributions by female authors is stricter than that of male authors. Consequently, in this case, the women's texts would be qualitatively more demanding than those of the men and this could counteract the quantitative discrepancy when it comes to the h-index. It could also mean that the articles finally published by women were more innovative than the ones published by males. It would be interesting to know how many women submitted articles and how high their $h$-index was in each case. The fact that we could not check these facts, limits our study at this point. By determining the $\mathrm{h}$-index of the authors from 2020, we can conclude that the women who published in 2020 did not undergo positive academic development overall. Whether they were forced out of research or what other potential reasons can be used as an explanation, cannot be answered based on our data. Only further research can provide well-founded insights here.

In order to be able to make statements about a targeted discrimination of female researchers in this context, it would be necessary to know how many women compared to men were rejected with their paper. Besides, to put our finding into an international context, it would be also necessary to know the corresponding numbers of female graduates in the field of mechanics from the respective countries of the authors concerned.

Even if the available figures on female graduates and doctoral candidates can only provide an orientation, they nevertheless allow initial conclusions to be drawn about an existing disproportion between the number of highly qualified women in engineering and the female authors in this field. The available figures from Germany, the European Union, and the USA provide a first indication that there does indeed seem to be a discrepancy between female authorship in the field of mechanics and the proportion of female graduates in this topic.

Although the proportion of female doctoral candidates in engineering has been consistently lower than that of males in recent years, it has also been consistently higher than the proportion of women who have published scientific papers during this period. If we compare all these figures with the female first authors from the journals we examined, a discrepancy requires closer examination. If less than $10 \%$ 
of women are first authors in two important and prestigious journals in the field of mechanics, although the proportion of female graduates in this field is more than twice as high, this requires closer examination. Meanwhile, the low number of women participating in the 2006 and 2017 Gamm seems to underscore the gap between male and female mechanics.

One possible explanation could be related to the results described by Joshi 2014 in his study: if the expertise of highly educated women was used to a greater extent in teams with a higher proportion of women than in teams composed of men, this could be the reason why women cannot assert themselves with their research to the same extent as men (Joshi 2014: 228). A field already dominated by men may not be so easy for women to pervade. In order to gain a deeper impression here, however, it would not only be important to know how many women submitted contributions at all during the periods examined, but also who the reviewers were. This might be difficult because the reviewer's identity mostly remains confidential. In his survey from 2004, Christoph Weller pointed out that the evaluation of scientific achievements is not regardless of gender. He notes that gender-specific imbalances exists in particular during the process of resubmitting for, since far fewer women than men make use of this possibility in the first place (Weller 2015). In 2015, Fox, Burns and Meyer found out, that female reviewers are a clear minority in the journal Functional Ecology. There it says: "The gender ratio of selected reviewers was also highly majority male, but the proportion of women selected as reviewers increased over the 10 years largely because the number of women on the editorial board increased and female editors invited more female reviewers than did male editors. Male editors selected $<25 \%$ female reviewers even in the year they selected the most women, but female editors consistently selected 30-35 \% female reviewers." (Fox et al. 2015). Women make up $2.4 \%$ of the Editorial Advisory Board at CMAME, and $7.1 \%$ at JMPS. It should be noted that just under $5 \%$ could not be assigned to a gender, as abbreviated first names did not provide a clear indication. In the managing editor of CMAME, one out of three persons is female. Of 6 associate editors at JMPS, one is female.

To know the number of male and female scientists that submitted a paper in the investigated period would allow us to draw conclusions about the quantity of men and women whose papers were rejected and whether there are significant differences. Another possible reason for the low number of female authors may be related to the journal editors. Holman, Fox and Hauser have stated in this regard: “Women were less often commissioned to write 'invited' papers, consistent with gender bias by journal editors, and were less often found in authorship positions usually associated with seniority" (Holman/Fox/Hauser 2018). Accordingly, especially high impact factors publish invited papers (Holman et al. 2018).

Among all issues, we examined were two special issues: Special Issue Biological Systems Dedicated to William S. Klug (February issue) Special Issue on Isogeometric Analysis: Progress and Challenges (April issue). Altogether 67 articles appeared in these two journals together with four first authors each. In 
direct comparison with the other editions of CMAME in 2017, this is a relatively high proportion of female first authors, averaging 2.9 female first authors per edition, as we can see in Table 2. Therefore, we cannot confirm this assumption at this point but due to the insufficient amount of data, it is not possible to falsify it either.

It should also be noted that the survey can only depict a snapshot in time, because the number of citations, for instance, is not fixed but is subject to a dynamic process. To classify our results in an overall social context, we would need to know more about the ratio of male to female graduates in the field of mechanics at international level. Besides, it would be interesting to learn more about the reviewer's gender ratio.

One further difficulty concerning our survey's interpretation is closely related to the h-index. It can be discussed how reliable it is as a measuring instrument if it does not consider self-citations. Moreover, there are slight deviations with regard to the h-index when comparing the data of Scopus, ResearchGate and GoogleScholar. In our study, we focused on the data of Scopus to ensure comparability for all authors.

The fact that we were not able to assign every author to one gender may seem to be problematic as well and at this point, we should take a closer look. If there were a woman behind every unknown author, this would bias our results. However, even in this case men would clearly dominated the field of publications. Furthermore, this restriction applies only to CMAME, since in JMPS for both 2002 and 2017 each author could be clearly assigned to one gender.

Moreover, name changes are a particular threat to significance in this study, as women are more likely to change their names over time than men are. This might be problematic especially with regard to the h-index and individual article citations.

There is a danger that individual authors are recorded twice in Scopus, for example, without the values being merged. Without any indication of a potential name change, it is not possible to record and correctly assign these authors. Finally, the following question should not be ignored either: How representative is the result of our study and does it show significance with regard to the engineering field as a central subject of the STEM-disciplines? Since in CMAME and JMPS mainly mechanical and computational engineering are thematically represented, one must be cautious about transferring our results to other areas. The proportion of female researchers in mathematics is significantly higher than the proportion of women in engineering, for instance. Therefore, our results cannot be transferred unconditionally to all areas, but give a clear indication of the underrepresentation of female first authors in the field of mechanical engineering. 


\section{Acknowledgments}

The work is funded by the Deutsche Forschungsgemeinschaft (DFG, German Research Foundation) Projektnummer 223500200 - TRR 136. We gratefully acknowledge the financial support of the subproject Ö. Special thanks to Professor Dr. Carsten Trunk of the TU IImenau and Professor Dr. Volker Mehrmann of the TU Berlin for their support delivering the used data.

\section{References}

Alber, G., D. Hummel, U. Röhr, M. Spitzner, and I. Stieß. 2018. „Geschlechtergerechtigkeit und Klimapolitik“. APuZ 21-23: 40-48. Retrieved 02.12.2020 from:

https://epub.wupperinst.org/frontdoor/deliver/index/docld/7008/file/7008_Alber.pdf.

Annesley, T.M. 2020. "Gender Authorship in the Field of Clinical Chemistry". The Journal of Applied Laboratory Medicine 5: 869-876.

https://doi.org/10.1093/jalm/jfaa096.

Beede, D., T. Julian, D. Langdon, G. McKittrick, B. Khan, and M. Doms. 2011. “Women in STEM: A Gender Gap to Innovation." SSRN Electronic Journal (November): 2-11.

https://dx.doi.org/10.2139/ssrn.1964782.

Bhagat, V. 2019. "Women Authorship of Scholarly Publications in STEMM: Authorship Puzzle". Feminist Research 2 (June): 66-77.

DOI: $10.21523 / G C J 2.18020204$.

Blickenstaff, J.C. 2005. “Women and science careers. Leaky pipeline or gender filter?" Gender and Education 17 (November): 369-386.

DOI: $10.1080 / 09540250500145072$.

Burke, R.J. 2007. "Women and minorities in STEM: a primer". In Women and minorities in Science, Technology, Engineering, and Mathematics. Upping the Numbers edited by E. Elgar, 3-28. Cheltenham/Northampton: Edward Elgar Publishing Inc.

Cardador, M.T., and P.L. Hill. 2018. "Career Paths in Engineering Firms: Gendered Patterns and Implications." Journal of Career 26 (December): 95-110.

https://doi.org/10.1177/1069072716679987. 
Carter, T.E., T.E. Smith, and P.J. Osteen. 2017. “Gender comparisons of social work faculty using HIndex scores". Scientometrics 111 (February): 1547-1557.

DOI: https://doi.org/10.1007/s11192-017-2287-0.

Destatis. Statistisches Bundesamt. 2021. Bildung und Kultur. Statistik der Promovierenden. wissen.nutzen.

Retrieved 04.02.2021 from:

https://www.destatis.de/DE/Themen/Gesellschaft-Umwelt/Bildung-Forschung-Kultur/Hochschulen/_inhalt.html\#sprg229108.

Destatis. Statistisches Bundesamt. Pressemitteilung. 2020.

Retrieved 05.07.2021 from:

https://www.destatis.de/DE/Presse/Pressemitteilungen/2020/10/PD20_409_213.html.

Destatis Statistisches Bundesamt 2014. Auf dem Weg zur Gleichstellung? Bildung, Arbeit und Soziales - Unterschiede zwischen Frauen und Männern.

Rerieved from 05.07.2021 from:

https://www.destatis.de/DE/Methoden/WISTA-Wirtschaft-und-Statistik/2014/08/weg-zur-gleichstellung-82014.pdf?_blob=publicationFile

Elomäki, A. 2015. "The economic case for gender equality in the European Union: Selling gender equality to decision-makers and neoliberalism to women's organizations". European Journal of Women's Studies 22 (February): 288-302.

DOI: $10.1177 / 1350506815571142$.

Etzkowitz, H., and M. Ranga. 2011: “Gender Dynamics in Science and Technology: From the "Leaky Pipeline to the "Vanish Box". Cahiers économiques de Bruxelles 54 (February): 131-147.

Retrieved 02.02.2021 from:

https://www.researchgate.net/publication/227379745_Gender_Dynamics_in_Science_and_Technology_From_the_Leaky_Pipeline_to_the_Vanish_Box?enrichld=rgreq-

3115a45df7b84b1ac42ab33618f908cf-XXX\&enrichSource=Y292ZXJQYWd-

IOzlyNzM3OTc0NTtBUzoxMDExOTAyMDk2Mzg0MjNAMTQwMTEz-

NzAzNTAyMQ\%3D\%3D\&el=1_x_2\&_esc=publicationCoverPdf. 
Eurostat. 2020. Employed HRST by category, sex, age, and NACE Rev. 2 activity (from 2008 onwards). Retrieved 01.10.2020 from:

http://appsso.eurostat.ec.europa.eu/nui/submitViewTableAction.do.

Eurostat. 2021. "Europa in Zahlen - Eurostat Jahrbuch 2010".

Retrieved 04.02.202 from:

https://ec.europa.eu/eurostat/documents/3217494/5719449/CH_04_2010-DE.PDF/6fde61eb-552b4aa6-bd7f-75e08f4e8392.

Filardo, G., B. da Graca, D.M. Sass, B.D. Pollock, E.B. Smith, and M.A.M. Martinez. 2016. "Trends and Comparison of female first authorship in high impact medical journals: observational study (19942014)." BMJ (March).

https://doi.org/10.1136/bmj.i847.

Fox, C.W., C.S. Burns, and J.A. Meyer. 2015. "Editor and reviewer influence the peer review process but not peer outcomes at an ecology journal". Functional Ecology 30 (August): 140-153.

https://doi.org/10.1111/1365-2435.12529.

Fouad, N.A., M.B. Kozlowski, R. Singh, N.G. Linnemann, S.S. Schams, and K. N. Weber. 2019. „Exploring the Odds. Gender Differences in Departing the Engineering Profession." Journal of Career Assessment 1-16 (September): 446-461.

https://doi.org/10.1177/1069072719876892.

GAMM - Gesellschaft für Angewandte Mechanik und Mathematik e.V. 2006. Book of Abstracts. 88th Annual Meeting of the International Association of Applied Mathematics and Mechanics (March). Technische Universität Ilmenau.

Geraci, L., S. Balsis, A.J. Busch Busch. 2015. „Gender and the h Index in psychology”. Scientometrics 105 (September): 2023-2034.

DOI: https://doi.org/10.1007/s11192-015-1757-5.

Gorlov, V. „Warum gibt es kaum Ingenieurinnen? Gründe für eine Geschlechts(un)spezifische Berufswahl. Deutschland und Schweden im Vergleich." Bamberger Beiträge zur Soziologie 4. 2009, Bamberg: University of Bamberg Press. 
Hatmaker, D.M. 2013. “Engineering Identity: Gender and Professional Identity Negotiation among Women Engineers." Gender, Work and Organization 20 (February): 382-396.

https://doi.org/10.1111/j.1468-0432.2012.00589.x.

Henwood, F. 2010. "Engineering Difference: Discourses on Gender, sexuality and work in a college of technology. Gender and Education 10 (July): 35-43.

https://doi.org/10.1080/09540259821087.

Herrmann, S.D., R.M. Adelmann, J.E. Bodford, O. Gradejus, M.A. Okun, and V.S.Y. Kwan. 2016. "The Effects of Female Role Model on Academic Performance and Persistence of Women in STEM courses". Basic and Applied Social Psychology (August): 258-268.

https://doi.org/10.1080/01973533.2016.1209757.

Herschberg, C., and Berger L.J. 2015. „Academic Careers and Gender Inequality: Leaky Pipeline and Interrelated Phenomena in Seven European Countries. GARCIA working papers https://hdl.handle.net/2066/181846.

Hill, C., C. Corbett, and A. S. Rose. "Why so few? Women in Science, Technology, Engineering, and Mathematics", Washington: AAUW. 2010.

Holmann, L., D. Steward Fox, and C.E. Hauser. 2018. "The Gender gap in science: How long until women are equally represented?" PLOS Biology. Retrieved 05.10.2020 from: https://journals.plos.org/plosbiology/article?id=10.1371/journal.pbio.2004956\#sec001 https://doi.org/10.1371/journal.pbio.2004956.

Joshi, A. 2014: "By Whom and When Is Women's Expertise Recognized? The Interactive Effects of Gender and Education in Science and Engineering Teams." Administrative Science Quarterly 59 (March): 202-239.

DOI: 10.1177/0001839214528331.

Kottmann, M., B. Kriegesmann, and F. Striewe. 2008. „Fachkräftemangel in Deutschland: Handlungsfelder für eine Neuausrichtung der beruflichen Bildung“. List Forum für Wirtschafts- und Finanzpolitik 34 (August): 56-70.

DOI: $10.1007 / B F 03373285$. 
Larivière, V., C. Ni, Y. Gingras, B. Cronin, and C.R. Sugimoto 2013. "Bibliometrics: Global ender disparites in science". Nature. International weekly journal of science 504 (December). Retrieved 07.102020 from: https://www.nature.com/news/bibliometrics-global-gender-disparities-in-science1.14321

Leicht-Scholten, C., E. Breuer, N. Tulodetzki, and A. Wolffram 2011. „Going Diverse. Innovative Answers To Future Challenges. Gender and Diversity Perspectives in Science", Technology and Business. Leverkusen: Budrich UniPress Ltd.

Leicht-Scholten, C. 2007: "Perspektiven in den Natur- und Ingenieurwissenschaften". Gender and Science. Bielefeld: Transkript verlag.

DOI: $10.14361 / 9783839406748$.

Lewis, K.L., J.G. Stout, N.D. Finkelstein, S.J. Pollock, A. Miyake, G.L. Cohen, and T.A. Ito. 2017. “Fitting into Move Forward. Belonging, Gender, and Persistence in the Physical Sciences, Technology, Engineering, and Mathematics (pSTEM)." Psychology of Women Quarterly 41: 420-436.

DOI: https://doi.org/10.1177/0361684317720186.

Maliniak, D., R. Powers, and B.F. Walter. 2013. "The Gender Citation Gap in International Relations". International Organization 67 (October): 889-922.

DOI: https://doi.org/10.1017/S0020818313000209.

Miller, D.I., and J. Wai. 2015: "The bachelor's to Ph.D. STEM pipeline no longer leaks more women than men. A 30-year analysis. frontiers in PSYCHOLOGY (February): 1-10.

DOI: 10.3389/fpsyg.2015.00037.

Nationaler Pakt für Frauen in MINT-Berufen. 2020. Promotionen im Studienbereich Maschinenbau/Verfahrenstechnik 1973 bis 2018 in Deutschland.

Retrieved 01.10.2020 from: https://www.komm-mach-mint.de/service/mint-datentool.

National Science Foundation. 2020. Master's degrees awarded to women, by field: 2004-14.

Retrieved 01.10.2020 from: https://www.nsf.gov/statistics/2017/nsf17310/static/data/tab6-2.pdf.

National Science Foundation. 2020. Doctoral degress' awarded to women, by field: 2004-2014.

Retrieved 01.10.2020 from:

https://www.nsf.gov/statistics/2017/nsf17310/static/data/tab7-2.pdf. 
National Center for Science and Engineering Statistics. Doctorate recipients, by subfield of study and sex: 2017. NSF 19-301. Retrieved 04.02.2021 from:

file://C:/Users/Kaesler/AppData/Local/Temp/sed17-sr-tab016.pdf.

National Science Foundation. 2021. Doctorate Recipients from United States Universities: Summary Report 2002. Retrieved 04.02.2021 from:

https://wayback.archive-it.org/5902/20150627194742/http://www.nsf.gov/statistics/doctorates/pdf/sed2002.pdf.

Pico, T., P. Bierman, K., Doyle, and S. Richardson. 2020. "First authorship gender gap in the geosciences." Earth and Space Science 7 (August): 1-7.

DOI: https://doi.org/10.1029/2020EA001203.

Quaiser-Pohl, C. "Mädchen und Frauen in MINT: Ein Überblick". In Mädchen und Frauen in MINT. Bedingungen von Geschlechtsunterschieden und Interventionsmöglichkeiten, edited by H. Stöger, A. Ziegler, and M. Heilemann, 13-41. Berlin: LIT Verlag.

Schubert, F., and S. Engelage. 2011. „Wie undicht ist die Pipeline? Wissenschaftskarrieren von promovierten Frauen. KZfSS Kölner Zeitschrift für Soziologie und Sozialpsychologie 63 (September): 431457.

Doi: 10.1007/s11577-011-0144-3.

Scimago Journal \& Country Rank SJR. 2019. Retrieved 23.10.2020 from:

https://www.scimagojr.com/journalrank.php?area=2200\&category=2206.

Sidhu, R., P. Rajashekhar, V. L. Lavin, J. Parry, J. Attwood, A. Holdcroft, and D.S. Sanders. 2009. "The gender imbalance in academic medicine: a Study of female authorship in the United Kingdom." Journal of the Royal Society of Medicine 102 (August): 337-342.

DOI: https://doi.org/10.1258/jrsm.2009.080378.

Society of Women Engineers. Higher Education. Tenure/ Tenure-Track Faculty Levels.

Retrieved from 05.07.2021 from:

https://research.swe.org/2016/08/tenure-tenure-track-faculty-levels/. 
Squazzoni, F., G. Bravo, M. Farjam, A. Marusic, B. Mehmani, M. Willis, A. Birukou, P. Dondio, and F. Grimaldo. 2021. "Peer review and gender bias: A study on 145 scholarly journals." Social Sciences 7 (January): 1-11.

DOI: $10.1126 /$ sciadv.abd0299.

Statista. 2021. Retrieved from 09.02.2021:

https://de.statista.com/statistik/daten/studie/197908/umfrage/frauenanteil-in-der-professorenschaft-nach-faechergruppen/.

Verdugo-Castro, S., M. Cruz Sánchez-Gómez, and A. García-Holgado. 2018. “Gender gap in the STEM sector in pre and university studies of Europe associated with ethnic factors". Proceedings of the Sixth International Conference on Technological Ecosystems for Enhancing Multiculturality (October): 984-990.

DOI: https://doi.org/10.1145/3284179.3284348.

Weller, C. 2004. "Beobachtungen wissenschaftlicher Selbstkontrolle. Qualität, Schwächen und die Zukunft des Peer-Review-Verfahrens." Zeitschrift für Internationale Beziehungen 11 (Dezember): 365394. Retrieved October 9, 2020, from http://www.jstor.org/stable/40843977.

West, J.D., J. Jacquet, M.M. King, S.J. Correll, and C.T. Bergstrom. 2013. "The Role of Gender in Scholarly Authorship." PLOS one 8 (July). Retrieved from: https://www.ncbi.nlm.nih.gov/pmc/articles/PMC3718784/.

DOI: https://doi.org/10.1371/journal.pone.0066212.

Williams. W.A., E.A. Kolek, D.B. Saunders, A. Remaly, and R.S. Wells. 2017. "Mirror on the field: Gender, Authorship, and Research Methods in Higher Education's Leading Journals." Journal of Higher Education 12 (June): 28-53.

DOI: https://doi.org/10.1080/00221546.2017.1330599.

Young, K., M. Lovedee-Turner, J. Brereton, and H. Daffern. 2018. "The impact of Gender of Conference Authorship in Audio Engineering: Analysis a New Data Collecting Method." IEEE TRANSACTIONS ON EDUCATION 61 (November): 328-335.

DOI: 10.1109/TE.2018.2814613. 
